\title{
Screening for obstructive sleep apnoea using the STOPBANG questionnaire and the Epworth sleepiness score in patients admitted on the unselected acute medical take in a UK hospital
}

\author{
Authors: Barney T J Isaac, ${ }^{A}$ Sarah E Clarke, ${ }^{B}$ Mohammad Saiful Islam ${ }^{C}$ and Johnson T Samuel ${ }^{D}$
}

\begin{abstract}
Obstructive sleep apnoea (OSA), which is often overlooked in patients presenting to primary and secondary care, is an increasingly common comorbidity. The prevalence of OSA has not been studied in the unselected acute medical take. The aim of this study was to screen for the prevalence of undiagnosed OSA using the STOPBANG Questionnaire and the Epworth sleepiness scale (ESS) score in an unselected acute medical take. This was a cross-sectional study in a busy UK general hospital. Patient demographics, comorbidities, ESS and STOPBANG scores on unselected acute medical takes were reviewed and analysed to assess the prevalence of OSA. Of 93 patients screened, more than $50 \%$ were obese. The STOPBANG score was $\geq 3$ in $73 \%$. The ESS was significantly increased $(\geq 11)$ in $20 \%$. On multivariate analysis, ESS continued to remain independently associated with the STOPBANG score with a p-value of 0.04 . The routine use of the STOPBANG questionnaire followed by an ESS score in those with a score of $\geq 3$ may focus evaluation for undetected OSA in the acute medical care setting.
\end{abstract}

KEYWORDS: Acute medicine, obstructive sleep apnoea, screening, sleepiness, STOPBANG

\section{Introduction}

Although obstructive sleep apnoea (OSA) and OSA syndrome (where OSA is associated with increased daytime sleepiness) have been recognised for over 40 years, OSA is significantly underdiagnosed and consequently not investigated. In western populations, about $2-4 \%$ of middle-aged men and $1-2 \%$ of middle-aged women have OSA, but in the majority of these

Authors: A specialty doctor, Basildon and Thurrock University Hospital, Basildon, UK; ${ }^{B}$ core medical trainee, Basildon and Thurrock University Hospital, Basildon, UK; ${ }^{C}$ specialty registrar (ST5), Basildon and Thurrock University Hospital, Basildon, UK; ${ }^{\mathrm{D}}$ consultant respiratory physician, Basildon and Thurrock University Hospital, Basildon, UK patients, OSA is undetected and is therefore not treated - even when they present to healthcare professionals. ${ }^{1,2}$ Over the last two decades, there has been a substantial increase in the prevalence of OSA. A recent study by Peppard et al, using data from the Wisconsin Sleep Cohort Study, estimated the prevalence of moderate or severe OSA to be $10-17 \%$ in men and $3-9 \%$ in women. ${ }^{3}$

OSA is strongly associated with obesity, but it is also increasingly seen in the less obese. Only about $50 \%$ of patients diagnosed at a large sleep clinic in Edinburgh in recent years were obese. ${ }^{4}$ There are increasing concerns about the health and economic impact of untreated OSA. Increased sleepiness impairs social functioning, work performance and driving ability. ${ }^{5}$ The long-term effects on health in those affected can consequently have a significant impact on the health status of the individuals affected and the socio-economic burden in the community.

Several studies have evaluated the associations of OSA with the development of cardiovascular and cerebrovascular disorders, including hypertension, stroke, ischemic heart disease and cardiac failure. OSA has been associated with the 'metabolic syndrome', ie central obesity, glucose intolerance and insulin resistance with significant independent implications on morbidity and mortality. A minority of patients with OSA develop pulmonary hypertension. In addition, neuropsychological manifestations - such as inattention, poor concentration, depression and diminution of sexual function have been described. Patients with OSA impose a significant burden on healthcare systems before the diagnosis is made, with greater average medical costs before diagnosis. Untreated OSA is estimated to have additional medical costs of up to $\$ 3.4$ billion per annum in the USA. ${ }^{6}$ The cost burden of OSA associated with poor workplace performance and high risk of road traffic accidents has not been fully assessed, but is likely to be significant.

While patients presenting routinely or acutely to healthcare providers are screened for risk factors such as smoking and alcohol consumption, those who may have OSA are not screened. Screening in specialty clinics, such as diabetes and heart failure clinics, have demonstrated a high prevalence of OSA. As most studies of OSA were in the clinically obese, 
the recognition of symptoms and signs of OSA in the less obese is negligible as demonstrated by the referral patterns to sleep clinics. There is also a misconception that OSA is predominantly a disorder in male patients; this often results in a gender bias in referral. A recent study in an unselected female population showed a significant prevalence of OSA in patients who did not report symptoms. ${ }^{7}$

We postulated that screening for OSA in patients attending the acute medical unit for a variety of medical conditions might give an idea of the scale of the problem in this unselected population seeking acute medical care. This could lead to early diagnosis and treatment for those affected. In addition, if the prevalence is significant in this cohort, actively looking for symptoms and signs of OSA may need to become part of normal practice in the acute medical setting.

The STOPBANG questionnaire includes loud snoring, tiredness, observed apnoea, high blood pressure (STOP), body mass index (BMI), age, neck circumference and gender (BANG). It is a validated screening tool for identifying OSA in surgical patients. ${ }^{8}$ and has shown to have good predictive value for detecting OSA in obese patients. ${ }^{9}$ It is a sensitive but not a specific screening tool for OSA. A score of 3 or more has a sensitivity of over $90 \%$ for OSA. ${ }^{9}$ However, this has not been studied in the acute medical admission setting. The Epworth sleepiness scale (ESS) score is a useful validated tool to assess sleepiness and has been used to initiate treatment for OSA syndrome. Hence, we used these two tools in our study.

\section{Aim}

The aim of this study was to screen for the prevalence of an elevated STOPBANG $(\geq 3)$ and the ESS score $(\geq 11)$, which predict a high risk for OSA in patients admitted to hospital via the unselected acute medical take.

\section{Methods}

Patients admitted to the acute medical unit in a UK general hospital for any medical reason from January to June 2014 were included in the study. This was a cross-sectional study and convenience sampling was adopted to fit with the clinical work of the authors. Assuming a prevalence of $50 \%$ with an absolute precision of 10 , allowing for an alpha error of $5 \%$ and a power of $80 \%$, we calculated a required sample size of 97 patients. The study was approved by our local institutional review board.

Patients attending the acute medical unit at Basildon Hospital are referred either from general practice or the accident and emergency department. Patients aged 30-75 years were prospectively included in the study by convenience sampling. They were excluded if they were previously diagnosed with OSA or obesity hypoventilation syndrome, if there was an obvious cause of hypoventilation such as chest wall deformities or neuromuscular disease, or if they were critically unwell and therefore unable to complete the questionnaire. Information regarding their demographic characteristics and comorbidities were also collected.

After obtaining written informed consent, participants completed a questionnaire. This questionnaire included the parameters of the STOPBANG and the ESS. For those patients who scored 3 or more on the STOPBANG score, their GPs were informed suggesting referral if appropriate. SPSS 16.0 software was used to analyse the data. Descriptive statistics were used for analysing the demographic data. The association between risk variables and STOPBANG were tested using Chi-square test with Yates correction. The variables that had significance of $\mathrm{p}<0.25$ at bivariate were considered for multivariate logistic regression analysis (parameters which were part of STOPBANG were not included in this). Results were presented with odds ratio (OR) and 95\% confidence interval (CI).

\section{Results}

In total, 93 patients were prospectively recruited during the study period. The commonest reason for admission was a respiratory cause $(21.5 \%) .67 \%$ of the patients were more than 50 years of age and $57 \%$ of the study participants were female. More than $50 \%$ of the patients were obese (BMI $>30)$. The commonest comorbidity was hypertension (39\%). The demographic data are given in Table 1 . The STOPBANG score was $\geq 3$ in $73 \%$ of all the patients. More than $60 \%$ of all the patients were over 50 years in age. The commonest symptoms were snoring and apneic spells, each occurring in over $60 \%$ of patients. The GPs of these patients were informed of the elevated STOPBANG score and, if appropriate, a referral to the sleep clinic was suggested to decide on the need for further evaluation. The ESS score was increased $(\geq 11)$ in $20 \%$ of patients.

The ESS was not associated with any of the baseline demographics or comorbidities (Table 2). However, current smokers had a statistically significant association with the STOPBANG score compared with people who had never smoked (Table 3 ). In addition, there was a significant associations between ESS and STOPBANG scores $(\mathrm{p}=0.02$, Table 3). For a multivariate analysis to estimate the true associations with STOPBANG score, BMI, age, gender and hypertension were not included as they are part of the STOPBANG score. Ex-smokers and smokers were grouped together for the multivariate analysis. Arrhythmias and diabetes were included for the multivariate analysis as they had a p-value of up to 0.25 and were clinically relevant. However, only ESS score was independently associated with the STOPBANG score $(\mathrm{p}=0.04$, Table 4$)$.

We also looked at the ability of STOPBANG to reflect a significantly elevated ESS. STOPBANG had a sensitivity of $95 \%$, specificity of $32 \%$, positive predictive value of $27 \%$ and a negative predictive value of $96 \%$ to reflect an elevated ESS. The positive and negative likelihood ratios were 1.4 and 0.16 , respectively. A positive STOPBANG had an odds ratio of 8.6 of predicting an elevated ESS score, but this had a wide confidence interval. The details are tabulated with the Youden index in Table 5.

\section{Discussion}

This is the first study to our knowledge attempting to estimate the prevalence of OSA in the acute medical care setting. We used two existing screening questionnaires:

\footnotetext{
$>$ STOPBANG, which has been validated in OSA

$>$ ESS, the well-established sleepiness score in OSA.
}

This study was designed to estimate the prevalence of positive STOPBANG and ESS scores to give an indication of the burden of OSA in this population. This could inform 
Table 1. Baseline characteristics

\begin{tabular}{|c|c|c|}
\hline Variables & Number $(n=93)$ & Percentage \\
\hline \multicolumn{3}{|l|}{ Age: } \\
\hline$\leq 50$ years & 31 & 33.3 \\
\hline$>50$ years & 62 & 66.7 \\
\hline \multicolumn{3}{|l|}{ Gender: } \\
\hline Male & 40 & 43.0 \\
\hline Female & 53 & 57.0 \\
\hline \multicolumn{3}{|l|}{ Reason for admission: } \\
\hline Respiratory & 20 & 21.5 \\
\hline Gastrointestinal & 14 & 15 \\
\hline Neurological & 12 & 12.9 \\
\hline Chest pain & 12 & 12.9 \\
\hline $\begin{array}{l}\text { Cardiac (cardiac failure, } \\
\text { arrhythmias) }\end{array}$ & 9 & 9.7 \\
\hline Renal & 4 & 4.3 \\
\hline Sepsis & 3 & 3.2 \\
\hline Thrombo-embolic & 3 & 3.2 \\
\hline Orthopedic & 3 & 3.2 \\
\hline Others & 13 & 14 \\
\hline \multicolumn{3}{|l|}{ Smoking: } \\
\hline Never smoked & 36 & 38.7 \\
\hline Ex-smoker & 30 & 32.3 \\
\hline Current smoker & 27 & 29.0 \\
\hline \multicolumn{3}{|l|}{ BMI: } \\
\hline Normal (18.5-24.9) & 15 & 16.1 \\
\hline Overweight (25-29.9) & 29 & 31.2 \\
\hline Obese $(\geq 30)$ & 49 & 52.7 \\
\hline \multicolumn{3}{|l|}{ Comorbidities: } \\
\hline Hypertension & 36 & 38.7 \\
\hline Arrhythmias & 14 & 15.1 \\
\hline Diabetes & 17 & 18.3 \\
\hline Ischaemic heart disease & 7 & 7.5 \\
\hline Chronic kidney disease & 8 & 8.6 \\
\hline Snoring & 60 & 64.5 \\
\hline Tiredness & 20 & 21 \\
\hline Observed apnoeas & 58 & 62.4 \\
\hline $\begin{array}{l}\text { Increased neck } \\
\text { circumference }\end{array}$ & 48 & 51.6 \\
\hline \multicolumn{3}{|l|}{ STOPBANG: } \\
\hline Negative $(<3)$ & 25 & 26.9 \\
\hline Positive $(\geq 3)$ & 68 & 73.1 \\
\hline \multicolumn{3}{|l|}{ ESS score: } \\
\hline Negative $(<11)$ & 74 & 79.6 \\
\hline Positive $(\geq 11)$ & 19 & 20.4 \\
\hline
\end{tabular}

Table 2. Association of ESS score with risk variables

\begin{tabular}{|c|c|c|c|c|c|}
\hline \multicolumn{6}{|c|}{ Univariate analysis } \\
\hline \multirow[t]{2}{*}{ Parameters } & \multicolumn{5}{|c|}{ ESS score } \\
\hline & $\begin{array}{c}\text { Negative } \\
(<11)\end{array}$ & $\begin{array}{c}\text { Positive } \\
(\geq 11)\end{array}$ & OR & $95 \% \mathrm{CI}$ & p-value \\
\hline
\end{tabular}

Age:

$\leq 50$

$\begin{array}{lllll}23 & 74.2 & 8 & 25.8 & 1.00\end{array}$

$>50$

$\begin{array}{lllllll}51 & 82.3 & 11 & 17.7 & 0.62 & 0.22-1.75 & 0.36\end{array}$

BMI:

$<25$

$\begin{array}{lllll}12 & 80.0 & 3 & 20.0 & 1.00\end{array}$

$\geq 25$

$\begin{array}{lllllll}62 & 79.5 & 16 & 20.5 & 1.03 & 0.26-4.10 & 0.96\end{array}$

Gender:

Male

$\begin{array}{lllllll}30 & 75.0 & 10 & 25.0 & 1.63 & 0.59-4.49 & 0.34\end{array}$

Female

$\begin{array}{lllll}44 & 83.0 & 9 & 17.0 & 1.00\end{array}$

Smoking:

$\begin{array}{llllll}\text { Never smoked } \quad 28 & 77.8 & 8 & 22.2 & 1.00\end{array}$

$\begin{array}{llllllll}\text { Ex-smoker } & 22 & 73.3 & 8 & 26.7 & 2.28 & 0.54-9.59 & 0.26\end{array}$

$\begin{array}{llllllll}\text { Current smoker } & 24 & 88.9 & 3 & 11.1 & 2.90 & 0.68-12.37 & 0.15\end{array}$

Hypertension:

$\begin{array}{llllllll}\text { Yes } & 28 & 77.8 & 8 & 22.2 & 1.19 & 0.43-3.33 & 0.73\end{array}$

$\begin{array}{llllll}\text { No } \quad 46 & 80.7 & 11 & 19.3 & 1.00\end{array}$

Arrhythmia:

$\begin{array}{llllllll}\text { Yes } & 12 & 85.7 & 2 & 14.3 & 0.61 & 0.12-2.98 & 0.54\end{array}$

$\begin{array}{llllll}62 & 78.5 & 17 & 21.5 & 1.00\end{array}$

Diabetes:

$\begin{array}{llllllll}\text { Yes } & 12 & 70.6 & 5 & 29.4 & 1.84 & 0.56-6.09 & 0.31\end{array}$

No $\quad \begin{array}{llllll}62 & 81.6 & 14 & 18.4 & 1.00\end{array}$

IHD:

$\begin{array}{llllllll}\text { Yes } & 4 & 57.1 & 3 & 42.9 & 3.28 & 0.67-16.13 & 0.13\end{array}$

No $\quad \begin{array}{llllll}70 & 81.4 & 16 & 18.6 & 1.00\end{array}$

CKD:

Yes

$\begin{array}{lllllll}6 & 75.0 & 2 & 25.0 & 1.33 & 0.25-7.20 & 0.74\end{array}$

No

$\begin{array}{lllll}68 & 80.0 & 17 & 20.0 & 1.00\end{array}$

$\mathrm{BMI}=$ body mass index; $\mathrm{CKD}=$ chronic kidney disease; $\mathrm{ESS}=$ Epworth

sleepiness score; $\mathrm{IHD}=$ ischaemic heart disease

further management and ascertain the need to screen for OSA presenting to acute care.

Interestingly, more than $50 \%$ of our patients were clinically obese and this indicates the higher incidence of acute medical problems in the obese. Increased BMI $(>25)$ had a trend towards significant association with the STOPBANG score $(\mathrm{p}=0.07)$; however, because it is also part of this score, it was not included for multivariate analysis. Of note, an elevated ESS score $(\geq 11)$ was equally prevalent in the groups with increased BMI and normal BMI (Table 2). Although our study subjects did not have sleep studies to evaluate this further, it highlights the increasingly recognised prevalence of OSA in the non-obese. 
Table 3. Association of STOPBANG with risk variables

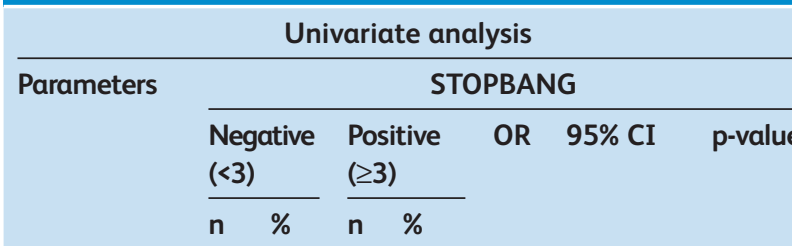

ESS score:

$\begin{array}{llllllll}\text { Negative }(<11) & 24 & 32.4 & 50 & 67.6 & 1.00 & & \\ \text { Positive }(\geq 11) & 1 & 5.3 & 18 & 94.7 & 8.64 & 1.09-68.58 & 0.04 \\ \text { Age: } & & & & & & & \\ \leq 50 & 12 & 38.7 & 19 & 61.3 & 1.00 & & 0.07 \\ >50 & 13 & 21.0 & 49 & 79.0 & 2.38 & 0.92-6.13 & \\ \text { BMI: } & & & & & & & \\ <25 & 7 & 46.7 & 8 & 53.3 & 1.00 & & \\ \geq 25 & 18 & 23.1 & 60 & 76.9 & 2.92 & 0.93-9.15 & 0.07 \\ \text { Gender: } & & & & & & & \\ \text { Female } & 18 & 34.0 & 35 & 66.0 & 1.00 & & \\ \text { Male } & 7 & 17.5 & 33 & 82.5 & 2.42 & 0.90-6.55 & 0.08 \\ \text { Smoking: } & & & & & & & \\ \text { Never smoked } & 8 & 22.2 & 28 & 77.8 & 1.00 & & \\ \text { Ex-smoker } & 5 & 16.7 & 25 & 83.3 & 2.80 & 0.94-8.35 & 0.06 \\ \text { Current smoker } & 12 & 44.4 & 15 & 55.6 & 4.00 & 1.18-13.60 & 0.03\end{array}$

Hypertension:

Yes

No

$\begin{array}{lllllll}7 & 19.4 & 29 & 80.6 & 1.19 & 0.71-5.18 & 0.20\end{array}$

$\begin{array}{lllll}18 & 31.6 & 39 & 68.4 & 1.00\end{array}$

Arrhythmia:

Yes

No

$\begin{array}{lllllll}2 & 14.3 & 12 & 85.7 & 2.46 & 0.51-11.89 & 0.25\end{array}$

$\begin{array}{lllll}23 & 29.1 & 56 & 70.9 & 1.00\end{array}$

Diabetes:

Yes

No

$\begin{array}{lllllll}2 & 11.8 & 15 & 88.2 & 3.26 & 0.69-15.40 & 0.12\end{array}$

$\begin{array}{lllll}23 & 30.3 & 53 & 69.7 & 1.00\end{array}$

IHD:

Yes

No

$\begin{array}{llllll}0 & 0.0 & 7 & 100.0 & - & -\end{array}$

0.10

CKD:

Yes

$\begin{array}{llll}25 & 29.1 & 61 & 70.9\end{array}$

No

$\begin{array}{llllll}0 & 0.0 & 8 & 100.0 & -\end{array}$

0.07

BMI = body mass index; $\mathrm{CKD}=$ chronic kidney disease; $\mathrm{IHD}=$ ischaemic heart disease; STOPBANG = loud snoring, tiredness, observed apnoea, high blood pressure, body mass index, age, neck circumference and gender

The other risk variable that was associated with STOPBANG was smoking $(\mathrm{p}=0.04)$. However, on multivariate analysis this was no longer significant, indicating that it was not independently associated with STOPBANG. This could be because of confounders or because of an inadequate sample size. Smoking has been known to be a risk factor for OSA. A case-control study in 2001 suggested current smokers have a
Table 4. Multivariate analysis of STOPBANG with

risk variables

$\begin{array}{llll}\begin{array}{l}\text { Parameters } \\ \text { ESS score: }\end{array} & \text { OR } & 95 \% \mathrm{CI} & \text { p-value } \\ \begin{array}{l}\text { Negative }(<11) \\ \text { Positive }(\geq 11)\end{array} & 1.00 & & \\ \text { Smoking: } & 8.23 & 1.03-66.47 & 0.04 \\ \text { Never smoked } & 1.24 & 0.44-3.49 & 0.68 \\ \text { Smoker } & 1.00 & & \\ \text { Arrhythmia: } & & & \\ \text { Yes } & 2.27 & 0.44-11.67 & 0.33 \\ \text { No } & 1.00 & & \\ \text { Diabetes: } & & & \\ \text { Yes } & 2.31 & 0.44-12.03 & 0.32 \\ \text { No } & 1.00 & & \end{array}$

2.8-times adjusted odds of having OSA than former smokers and 2.5-times adjusted odds compared with former smokers and never smokers. ${ }^{10}$ A review in 2012 looking at the association between smoking and OSA concluded that smoking may be a risk factor for OSA, but also raised the possibility of OSA being a risk factor for smoking addiction. ${ }^{11}$ Although not statistically significant, being over the age of 50 years and male gender had a trend towards association with STOPBANG; however, as these are part of the STOPBANG score, they are not discussed further. $73 \%$ of our patients had a positive STOPBANG $(\geq 3)$ indicating that nearly three-quarters of this population could potentially be screened for OSA. However, only $20 \%$ scored $\geq 11$ on the ESS, indicating that only one fifth of patients in the study had excessive daytime somnolence. Only one patient with an elevated ESS score had a negative score using the STOPBANG questionnaire; this suggests that STOPBANG is a good screening test to pick up almost all patients who have excessive daytime somnolence. This is further demonstrated by its high sensitivity (95\%) and negative predictive value (96\%) in reflecting an elevated ESS score, as shown in Table 5. STOPBANG has been shown to be a better screening score in the sleep clinic compared with ESS, Berlin questionnaire and STOP questionnaire. It had a sensitivity of $94.9 \%, 96.5 \%$

Table 5. Point estimates and $95 \%$ confidence intervals of STOPBANG versus ESS

True prevalence
Sensitivity
Specificity
Positive predictive value
Negative predictive value
Positive likelihood ratio
Negative likelihood ratio
Odds ratio
Youden index

$0.204(0.128-0.301)$

$0.947(0.74-0.999)$

$0.324(0.22-0.443)$

$0.265(0.165-0.386)$

$0.96(0.796-0.999)$

$1.402(1.159-1.696)$

$0.162(0.023-1.125)$

$8.64(1.088-68.584)$

$0.272(-0.04$ to 0.442$)$ 
and $97.7 \%$ in predicting mild, moderate and severe OSA, respectively. ${ }^{12}$ Our study suggests it can be used as a screening tool in the acute medical care setting as well.

\section{Limitations}

One limitation of our study was that patients did not have a sleep study to diagnose OSA. This would have been the gold standard to compare the screening questionnaire, giving a better estimate of the prevalence of OSA. However, this was not the aim of the study. As part of good clinical practice, the GPs of all patients who scored 3 or more on the STOPBANG score $(73 \%)$ were informed, so that they could initiate further referral as appropriate. The second limitation of the study was that patient recruitment during the study period was neither consecutive nor randomly sampled. This could have caused a sampling bias due to convenience sampling. However, as the daily admission lists are relatively similar this may not be a bias.

\section{Conclusions}

Almost three-quarters of patients on our unselected acute medical take had a positive STOPBANG score, which had high sensitivity in predicting an elevated ESS score. Further research with sleep studies on those who have a positive STOPBANG score to give an accurate indication of the prevalence of OSA in those presenting to acute medical units is warranted. However, the data suggest it is not unreasonable to proactively look for symptoms of OSA on the acute medical take as there are implications for patients' health and the wider health economy. Should this become part of normal practice in the future, it is likely that STOPBANG could be a good screening tool in this setting.

\section{Conflicts of interest}

The authors have no conflicts of interest to declare.

\section{Author contributions}

All authors were responsible for designing the study, data acquisition and the literature search. BTJI prepared the initial manuscript and all authors were involved in reviewing and editing it.

\section{Acknowledgement}

The authors would like to thank Mr Bijesh Yadav, the biostatistician who helped with the statistics in the study.

\section{References}

1 Young T, Peppard PE, Gottlieb DJ. Epidemiology of obstructive sleep apnoea: a population health perspective. Am J Respir Crit Care Med 2002;165:1217-39.

2 Stradling JR, Davies RJ. Sleep. 1: Obstructive sleep apnoea/ hypopnoea syndrome: definitions, epidemiology, and natural history. Thorax 2004;59:73-8.

3 Peppard PE, Young T, Barnet JH et al. Increased prevalence of sleep-disordered breathing in adults. Am J Epidemiol 2013;177:1006-14.

4 Mortimore IL, Marshall I, Wraith PK, Sellar RJ, Douglas NJ. Neck and total body fat deposition in nonobese and obese patients with sleep apnoea compared with that in control subjects. Am J Respir Crit Care Med 1998;157:280-3.

5 Ulfberg J, Carter N, Talbäck M, Edling C. Excessive daytime sleepiness at work and subjective work performance in the general population and among heavy snorers and patients with obstructive sleep apnoea. Chest 1996;110:659-63.

6 Kapur V, Blough DK, Sandblom RE et al. The medical cost of undiagnosed sleep apnoea. Sleep 1999;22:749-55.

7 Franklin KA, Sahlin C, Stenlund H, Lindberg E. Sleep apnoea is a common occurrence in females. Eur Respir J 2013;41:610-5.

8 Chung F, Yegneswaran B, Liao P et al. STOP questionnaire: a tool to screen patients for obstructive sleep apnea. Anesthesiology 2008;108:812-21.

9 Chung F, Yang Y, Liao P. Predictive performance of the STOP-Bang score for identifying obstructive sleep apnea in obese patients. Obes Surg 2013;23:2050-7.

10 Kashyap R, Hock LM, Bowman TJ. Higher prevalence of smoking in patients diagnosed as having obstructive sleep apnea. Sleep Breath 2001;5:167-72.

11 Lin YN, Li QY, Zhang XJ. Interaction between smoking and obstructive sleep apnea: not just participants. Chin Med J 2012;125:3150-6.

12 Luo J, Huang R, Zhong X, Xiao Y, Zhou J. STOP-Bang questionnaire is superior to Epworth sleepiness scales, Berlin questionnaire, and STOP questionnaire in screening obstructive sleep apnea hypopnea syndrome patients. Chin Med J 2014;127:3065-70.

Address for correspondence: Dr Barney T J Isaac, Department of Pulmonary Medicine, Christian Medical College, Vellore 632004, India.

Email: barneyisaac98@gmail.com 